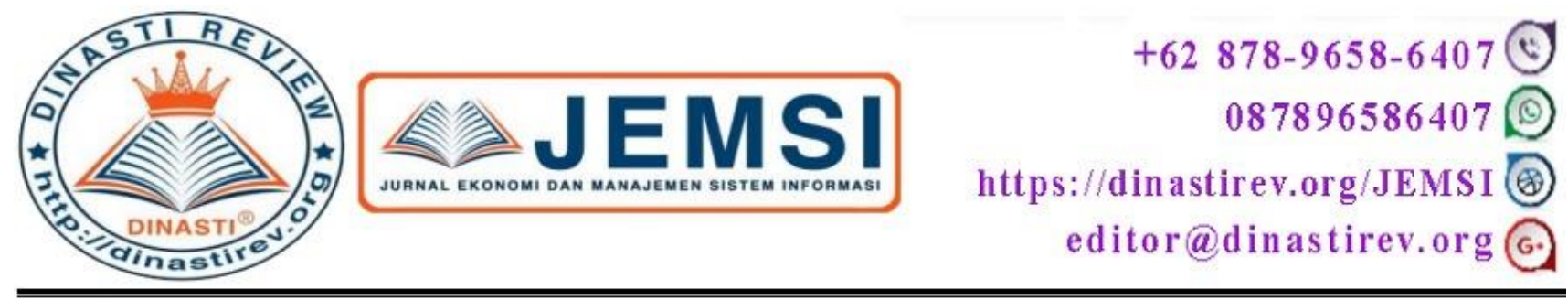

\title{
ANALISIS PENERAPAN ETIKA BISNIS PADA PT TELEKOMUNIKASI INDONESIA, Tbk
}

\section{Wahyu Samari}

Universitas Mercu Buana, Jakarta, Indonesia

\begin{tabular}{|c|c|}
\hline $\begin{array}{l}\text { ARTICLE INFORMATION } \\
\text { Received: } 26 \text { April } 2020 \\
\text { Revised: } 20 \text { Juni } 2020 \\
\text { Issued: } 7 \text { Juli } 2020\end{array}$ & $\begin{array}{l}\text { Abstrak: Perusahaan apapun dan dimanapun dalam } \\
\text { menjalankan bisnisnya pasti terikat dalam suatu aturan atau } \\
\text { norma yang berlaku di tempat tersebut atau di lingkungan } \\
\text { bisnis tersebut dijalankan. Baik besar ataupun kecil perusahaan } \\
\text { itu, norma bisnis tetap ada dan mengikat para pihak yang } \\
\text { terlibat di dalamnya. Penerapan norma atau aturan tersebut } \\
\text { adalah cerminan dari penerapan adanya etika bisnis pada } \\
\text { perikatan tersebut. Di Telkom, nilai-nilai etika bisnis yang } \\
\text { dibangun adalah Integritas, Enthusiasme, Totalitas. Nilai-nilai } \\
\text { ini dipandang sebagai nilai yang cocok dan pas } \\
\text { diimplementasikan di Telkom dengan melihat latar belakang } \\
\text { yang telah terjadi di Telkom. Penelitian ini merupakan } \\
\text { penelitian deskriptif yang akan menjelaskan lebih detail } \\
\text { mengenai implementasi dari nilai-nilai etika bisnis Telkom } \\
\text { diatas oleh seluruh stakeholders dalam menjalankan bisnis. } \\
\text { Data yang terangkum berdasarkan pada data historis karyawan } \\
\text { Telkom yang diadministrasikan oleh unit Human Capital } \\
\text { Business Partner (HCBP). Dari data diatas dapat disampaikan } \\
\text { bahwa implementasi etika bisnis sudah dijalankan di Telkom } \\
\text { dan telah dilakukan secara berkala. Dengan implementasi etika } \\
\text { bisnis belum ada karyawan yang melakukan tindakan tidak } \\
\text { terpuji yang dapat merusak hubungan bisnis antar } \\
\text { stakeholders. } \\
\text { Kata kunci: etika bisnis, good corporate governance }\end{array}$ \\
\hline
\end{tabular}

\section{PENDAHULUAN}

Baru-baru ini kita mendapatkan berita adanya kasus penipuan Travel Umroh First Travel dan beberapa kasus serupa lainnya. Belum lama juga kita mendengar kasus perijinan kawasan terpadu Meikarta yang sampai melibatkan pejabat publik suatu daerah. Lebih terbaru lagi kasus yang terjadi pada para endorser-endorser produk online yang saat ini kasusnya sedang ada di pihak 
kepolisian. Apa yang sebenarnya terjadi pada bisnis-bisnis tersebut? Apa yang dilanggar sehingga dampaknya merugikan konsumen, investor dan juga masyarakat banyak? Dan sampai akhirnya berdampak hukum pada para pelakunya. Jika diperhatikan lebih lanjut, perusahaan-perusahaan tersebut akan mengalami penurunan reputasi, kurang dipercaya, dan turunnya kinerja keuangan mereka. Padahal sangat sulit untuk mengembalikan kepercayaan para stakeholders jika sudah terjadi yang demikian. Jika kita perhatikan, bisa kita pastikan perusahaan-perusahaan tersebut memiliki sistem nilainya masing-masing dimana nilai-nilai tersebut memiliki arti yang sangat baik. Lalu apa yang terjadi dengan nilai-nilai tersebut?

Sebuah perusahaan yang baik akan dijalankan dengan prinsip-prinsip pengelolaan yang baik (good governance). Prinsip penegakan good governance adalah dengan mewujudkan perilaku karyawan, pemimpin, serta pihak-pihak yang terkait untuk senantiasa patuh pada norma, kaidah dan etika dalam bentuk budaya perusahaan. Dalam rangka mengimplementasikan budaya perusahaan khususnya untuk mewujudkan perilaku bisnis yang beretika maka diperlukan panduan yang bersifat mengikat dalam bentuk kebijakan Good Corporate Governance. Dan guna memastikan efektifitas implementasi Good Corporate Governance diperlukan penerapan kebijakan etika bisnis dalam rangka mewujudkan bisnis yang berkinerja unggul, berkesinambungan dan dijalankan dengan menaati kaidah-kaidah etika yang sejalan dengan hokum dan peraturan yang berlaku.

Dilihat dari kasus-kasus diatas, beberapa symptom bisa dikemukakan untuk perusahaan tersebut, yaitu :

1. Belum adanya good corporate governance

2. Belum adanya budaya perusahaan

3. Belum adanya kebijakan yang mengikat untuk menjalankan good governance itu

Bisa dikatakan bahwa perusahaan-perusahaan tersebut belum menjalankan tata kelola perusahaan atau good corporate governance dengan baik. Oleh karenanya penerapan kebijakan etika bisnis dan good governance pada perusahaan dalam menjalankan bisnisnya menjadi penting. Dengan implementasi etika bisnis, maka aspek-aspek moral lebih ditekankan dalam menjalankan bisnis dan sistem ekonomi secara keseluruhan. Dengan etika bisnis dan good governance ada kebijakan-kebijakan yang mengikat seluruh komponen di dalam perusahaan tersebut untuk berperilaku sesuai nilai-nilai yang diusung perusahaan tersebut.

Etika bisnis menjadi persoalan yang cukup penting dalam kegiatan bisnis. Dalam praktek bisnis akan muncul dua kepentingan yang saling bertolak belakang yaitu keinginan pelaku usaha untuk berhasil dalam mendapatkan keuntungan di satu sisi, serta harapan konsumen untuk mendapat produk yang baik dengan harga yang ekonomis di sisi lainnya. Pelaku usaha berupaya mencapai kepentingannya dengan berbagai cara sehingga dapat saja mengabaikan kepentingan pihak-pihak lain, termasuk konsumen. Ini realitas bisnis yang jika tidak dikelola dengan baik justru akan merugikan semua pihak dalam pandangan obyektif etika terkait dengan keuntungan perusahaan. Sebaliknya jika tidak mengikuti aturan main bisnis pada dasarnya seperti memastikan kerugian (Skrabec, 2003). 
Untuk mengimplementasikan etika bisnis, ada beberapa hal yang perlu untuk diperhatikan, yaitu:

1. Pengendalian diri

2. Implementasikan juga Tanggung Jawab Sosial Perusahaan

3. Menguatkan dan menegakkan identitas nasional / perusahaan

4. Menolak 5K (katabelece, kongkalikong, koneksi, kolusi, dan komisi)

5. Bertahan pada prinsip kebenaran

6. Menguatkan sikap saling percaya

7. Konsekuen dan konsisten dengan aturan yang dibuat Bersama

8. Etika bisnis bersifat mengikat dan bisa menjadi hokum positif

Di Telkom, dasar melakukan kegiatan bisnis adalah integritas, enthusiasme, dan totalitas. Sedangkan caranya adalah dengan solid, speed, dan smart. Nilai-nilai ini telah diolah sedemikian rupa sehingga cocok untuk diterapkan di Telkom. Telkom membuat aturan selevel Peraturan Direktur Utama (PD) dan Peraturan Direktur (PR) terkait etika bisnis di Telkom. Hal ini menandai sangat pentingnya etika bisnis bagi Telkom. Peraturan ini mengatur hubungan internal dan juga hubungan ke pihak eksternal. Dalam PD tentang Etika Bisnis Telkom, Etika Bisnis dibagi menjadi 2 yaitu :

1. Etika Usaha

2. Etika Kerja Karyawan

Etika Usaha yaitu sistem nilai atau norma yang dianut oleh perusahaan sebagai acuan perusahaan, manajemen, dan karyawannya untuk berhubungan dengan lingkungannya dengan lingkup :

1. Hubungan dengan regulator

2. Hubungan dengan stakeholders

3. Ketentuan tambahan

Sedangkan Etika Kerja Karyawan adalah sistem nilai atau norma yang digunakan oleh seluruh karyawan dan pimpinan dalam bekerja sehari-hari dengan lingkup sebagai berikut :

1. Perilaku Utama Karyawan

a. Kapasitas dan kapabilitas karyawan

b. Kewajiban dan larangan

c. Kerahasiaan Informasi

d. Infrastruktur

e. Lingkungan kerja

2. Perilaku Utama Pimpinan

a. Perilaku Pemimpin

b. Perilaku Direksi

c. Perilaku Chief Executive Officer (CEO) dan Chief Financial Officer (CFO) 
Implementasi nyata bahwa Telkom telah menjalankan etika bisnis secara terus-menerus, tercatat dan selalu memperbaiki yang ada adalah para karyawan Telkom diwajibkan menandatangani Pakta Integritas setiap tahunnya. Sebelum Pakta Integritas ini ditandatangani, maka setiap karyawan wajib menjawab dengan benar beberapa pertanyaan terkait aturan etika bisnis dan good corporate governance. Selain itu, karyawan level tertentu wajib melaporkan harta dan kekayaannya kepada KPK. Karyawan juga mendeklarasikan bahwa proses bisnis kegiatan usaha yang dilakukan telah dan terus menerus dikontrol dan diperbaiki yaitu dengan deklarasi $\boldsymbol{C S A}$ Passed (control self assessment).

\section{KAJIAN PUSTAKA}

Etika bisnis merupakan studi yang dikhususkan mengenai moral yang benar dan salah. Studi ini berkonsentrasi pada standar moral sebagaimana diterapkan dalam kebijakan, institusi, dan perilaku bisnis (Velasquez, 2005).

Tata kelola Perusahaan yang Baik (Good Corporate Governance) adalah konsep yang dirumuskan demi peningkatan kinerja perusahaan melalui bimbingan atau pengawasan kinerja manajemen dan menjamin akuntabilitas manajemen terhadap stakeholdesr dengan mendasarkan pada aturan formal peraturan (Nasution dan Setiawan, 2007)

Tujuan etika bisnis adalah menggugah kesadaran moral para pelaku bisnis untuk menjalankan good business dan tidak melakukan monkey business atau dirty business. Etika bisnis mengajak para pelaku bisnis mewujudkan citra dan manajemen bisnis yang baik (etis) agar bisnis itu pantas dimasuki oleh semua orang yang mempercayai adanya dimensi etis dalam dunia bisnis. Hal ini sekaligus menghalau citra buruk dunia bisnis sebagai kegiatan yang kotor, licik, dan tipu muslihat. Kegiatan bisnis mempunyai implikasi etis, dan oleh karenanya membawa serta tanggungjawab etis bagi pelakunya.

Prinsip-prinsip Etika Bisnis menurut Muslich, 1998:

1. Prinsip Otonomi : Perusahaan bebas memiliki wewenang sesuai dengan bidang yang dilakukan dan pelaksanaan nya sesuai visi dan misi yang dimilikinya.

2. Prinsip Kejujuran : merupakan nilai yang paling mendasar dalam mendukung keberhasilan suatu perusahaan

3. Prinsip Tidak Berniat Jahat

4. Prinsip Keadilan : Perusahaan harus bersikap adil kepada pihak-pihak yang terkait dengan sistem bisnis

5. Prinsip Hormat Pada Diri Sendiri : Perusahaan harus bersikap adil kepada pihak-pihak yang terkait dengan sistem bisnis, menjaga citra baik perusahaan tersebut melalui prinsip kejujuran, tidak berniat jahat dan prinsip keadilan

Menurut Stephen R. Covey : honesty is telling the truth, in other word, conforming our words reality-integrity is conforming to our words, in other words, keeping promises and ful-filling expectations." Kejujuran berarti menyampaikan kebenaran, ucapannya sesuai dengan kenyataan. Sedang integritas membuktikan tindakannya sesuai dengan ucapannya. Orang yang memiliki 
integritas dan kejujuran adalah orang yang merdeka. Mereka menunjukan keauntetikan dirinya sebagai orang yang tanggung jawab dan berdedikasi. Enthusiasme adalah adanya rasa bersemangat dalam mengerjakan sesuatu, kegairahan yang kuat terhadap salah satu sebab (Sucipto Ajiksaka, 2008). Sedangkan Totalitas diartikan sebagai keadaan positif, keadaan, kepuasan, yang berhubungan dengan pikiran dalam bekerja dan ditandai dengan ketahanan mental yang tinggi, keadaan yang sangat terlibat dengan pekerjaan, dan sepenuhnya terkonsentrasi dengan pekerjaan (Schaufeli, 2014).

Perilaku etis tidak terlepas dari nilai-nilai yang menjadi keyakinan karyawan. Pentingnya perilaku etis pada organisasi semakin nyata dengan banyak penelitian terbaru yang menghasilkan pengetahuan yang terkait dengan organisasi dan manajemen (Trevino, Weaver dan Reynolds, 2006). Ketiga nilai dasar etika bisnis Telkom harus terimplementasikan oleh seluruh karyawan Telkom agar tercipta keseragaman kualitas dalam pelayanan kepada shareholders dan kastamer.

\section{METODE PENELITIAN}

Penelitian ini menggunakan penelitian deskriptif yaitu menunjukkan jika tujuan penelitian ialah agar bisa memberikan sebuah penjelelasan yang kian rinci lagi serta lebih mendalam tentang suatu masalah sosial yang dapat di jadikan sebagai objek penelitian. Kekuatan dari penelitian deskriptif ini ada dalam kualitas dan kuantitas kalimat yang nantinya akan di paparkan di dalam bab hasil sebuah penelitian.

Sumber data berasal dari sumber data primer yang terdokumentasi dengan baik, berupa dokumen Pakta Integritas dan CSA Passed.

\section{HASIL DAN PEMBAHASAN}

\section{Perilaku Utama Karyawan}

Kapasitas dan kapabilitas karyawan memiliki arti bahwa setiap karyawan Telkom wajib:

1. Memiliki keyakinan dasar yang senantiasa memiliki keinginan untuk memberi yang terbaik dalam setiap pekerjaan yang dilakukan

2. Menjunjung tinggi nilai-nilai kejujuran dalam niat, pikiran dan perbuatan pada setiap pekerjaan yang dilakukan

3. Memiliki kesungguhan dalam meningkatkan dan memelihara seluruh kapasitas dan kapabilitas pribadi yang mencakup aspek competence dan character melalui jalur formal dan informal.

Karyawan Telkom memiliki kewajiban dan larangan.

1. Wajib tunduk dan patuh pada peraturan perusahaan dan undang-undang yang berlaku.

2. Karyawan dan keluarga juga wajib menghindari benturan kepentingan individu dengan perusahaan.

3. Karyawan juga dilarang menerima gratifikasi

4. Karywan dilarang memasarkan produk dari perusahaan pesaing

5. Karyawan dilarang bekerja di perusahaan pesaing

6. Karyawan wajib menjadikan waktu kerjanya produktif. 
Terkait kerahasiaan informasi, karyawan :

1. Wajib melindungi dan tidak membocorkan informasi rahasia perusahaan kepada siapapun

2. Dilarang berdiskusi terkait informasi rahasia perusahaan kepada mitra, pesaing, perusahaan lain, serta pihak eksternal yang tidak terkait

3. Memiliki kewenangan akses informasi sesuai lingkup kerjanya

Terkait infrastruktur yang dimiliki Telkom, karyawan :

1. Wajib enjaga asset perusahaan dari pihak-pihak yang mencoba mengambil alih atau merusak asset perusahaan

2. Tidak diijinkan secara langsung maupun tidak langsung menjual, membeli, mengadakan, menyewakan atau meminjamkan asset perusahaan kepada pihak eksternal

3. Memaksimalkan asset perusahaan untuk kepentingan bisnis perusahaan

4. Dilarang menggunakan asset untuk kegiatan yang tidak wajar

Dalam rangka membangun lingkungan kerja yang fair dan sehat, karyawan wajib melaksanakan prinsip-prinsip:

1. Menguatkan kekompakan dan saling percaya antar karyawan

2. Meningkatkan kecepatan dalam merespon peluang bisnis dan memberikan layanan kepada pelanggan

3. Meningkatkan kreatifitas dan inovasi dalam melaksanakan pekerjaan

Semua aturan dan kebijakan etika bisnis tersebut selain ada kewajiban dan larangan, dalam prakteknya, seluruh karyawan Telkom diminta untuk menandatangani dokumen Pakta Integritas. Dalam dokumen itu menyatakan bahwa seluruh karyawan Telkom berjanji dan mendeklarisikan bahwa telah menjalan seluruh aturan dan kebijakan etika bisnis perusahaan dengan baik dan benar.

Selain itu untuk akuntabilitas penggunaan keuangan perusahaan secara good governance, karyawan level tertentu yang diberi tanggungjawab dalam pengelolaan keuangan perusahaan menandatangani dokumen CSA (control self assessment) secara online atau digital. Dokumen CSA ini berisi pernyataan bahwa karyawan tersebut telah menjalankan pengelolaan keuangan dengan prinsip-prinsip pengelolaan yang telah distandarisasi di Telkom.

Dari data Pakta Integritas dan CSA Passed didapati bahwa seluruh karyawan mengisi dan menandatangani Pakta Integritas dan CSA Passed. Dalam aspek Integritas, didapati bahwa aspek pelayanan kepada kastamer (baik eksternal dan internal) berjalan baik walaupun belum sempurna sesuai kaidah dalam PD tentang Etika Bisnis Telkom. Permasalahan data menjadi isu yang harus diperbaiki dalam salah satu nilai dasar etika bisnis ini. Aspek ini dinilai dan dievaluasi secara berkelanjutan. Masing-masing atasan berkewajiban memberi arahan dan mengevaluasi bawahannya minimal sekali dalam setahun. Kelalaian karyawan dalam aspek integrasi ini bisa mendapatkan hukuman dari perusahaan setelah terlebih dahulu diproses untuk ditentukan tingkat pelanggarannya, apakah ringan, sedang, atau berat. 
Enthusiasme karyawan cukup tinggi dikarenakan layanan yang kita hasilkan harus dapat dinikmati dengan cepat dan dalam kualitas baik ke pelanggan. Sistem informasi sudah terbangun baik, aliran proses bisnis berjalan baik. Dengan sistem informasi yang baik, pekerjaan yang sifatnya rutin bisa diambil alih oleh sistem informasi ini. Hasilnya beberapa pekerjaan yang sifatnya rutin sudah tidak lagi dikerjakan oleh SDM. Untuk menjaga ini, maka setiap karyawan harus ikut menjaga. Salah satunya adalah menjaga agar password sistem informasi seseorang tidak diketahui orang lain dan tidak boleh 'dipinjamkan' kepada orang lain. Harus dikurangi kegiatan yang bersifat rutin agar selalu tercipta kondisi yang sangat enthusiasm.

Nilai Totalitas bisa terlihat dari kehadiran karyawan, jam kedatangan dan jam pulang karyawan yang terekam baik di sistem informasi Telkom. Terlihat juga dari penyelesaian aktivitas yang berhubungan dengan pihak eksternal yang tidak akan berhenti sebelum dinyatakan selesai oleh pihak kastamer misalnya dalam kegiatan perbaikan gangguan. Totalitas ini ditandai dengan adanya monitoring 24 jam sehari dan 7 hari dalam seminggu untuk layanan kepada kastamer. Review dan peningkatan kualitas dilakukan terus menerus karena aktivitas mengawal layanan dilakukan 24 jam sehari dan 7 hari dalam seminggu.

Dalam hal pelayanan kepada kastamer eksternal, semua data sudah sangat transparan, dapat dimonitor oleh teknisi, unit pelayanan pelanggan dan kastamernya sendiri.

\section{KESIMPULAN DAN SARAN}

\section{KESIMPULAN}

1. Sebagai perusahaan terbuka, Telkom telah memilih nilai dasar etika bisnis yang sesuai yaitu Integritas, Enthusiasme, dan Totalitas. Ketiga nilai ini diperlukan karena sifat layanannya yaitu telekomunikasi

2. Implementasi Etika Bisnis mendukung terciptanya Good Corporate Governance di Telkom. Penerapan Etika Bisnis di Telkom sudah komprehensif karena sudah meliputi implementasi kepada Kastamer, Mitra, dan stakeholders lainnya

3. Dalam penerapan Integritas, Telkom cukup baik karena menyampaikan kepada stakeholders sesuai dengan realitasnya

4. Dalam penerapan Enthusiasme, sesuai bidangnya, maka Telkom mengembangkan Sistem Informasi untuk kebutuhan aktivitas bisnisnya. Hal ini menumbuhkan enthisiasme yang tinggi karena hal-hal yang sifatnya rutin bisa dikerjakan oleh sitem tersebut

5. Dalam penerapan Totalitas, Telkom sangat baik ditandai dengan adanya fungsi control layanan selama 24 jam sehari dan 7 hari seminggu

\section{SARAN}

1. Nilai-nilai dasar tadi harus ditelaah lebih lanjut karena seyogyanya harus bisa dihubungkan dengan adanya perbaikan disisi kinerja perusahaan secara keseluruhan

2. Kepercayaan investor harus bisa dinilai dengan penerapan etika bisnis di Telkom 


\section{DAFTAR RUJUKAN}

1. PD 201/2014 : Etika Bisnis di Lingkungan Telkom Group

2. Prof Hapzi Ali, 'Concepts and Theories of Business Ethics', Universitas Mercu Buana, 2020

3. Riane Jhonly Pio, Johny Revo Elia Tampi, 2018, 'Persepsi Karyawan Tentang Etika Bisnis (Studi pada PT Angkasa Pura I Bandar Udara Sam Ratulangi)'

4. N.Nuryesrnan M, Moral dan Etika Dalam Dunia Bisnis, Bank dan Manajemen, Mei/Juni 1996

5. Purba Victor, Hukum Bisnis Dalam Kegiatan Bisnis Para Manajer, Manajemen, 1993 